\title{
A cultura medicalizante e os processos transgeracionais
}

\section{The medicalizing culture and the transgenerational process}

\section{La cultura medicalizante y la proceso transgeneracional}

\author{
Luciana Jaramillo Caruso Azevedo $1 \stackrel{\mathrm{ORCID}}{\text {, Terezinha Féres Carneiro }} \underline{\text { ORCID }}$ \\ Pontifícia Universidade Católica do Rio de Janeiro - PUC-Rio \\ Brasil
}

Fecha correspondencia:

Recibido: marzo 13 de 18 de 2017.

Aceptado: noviembre 29 de 2018.

Forma de citar:

Azevedo, L.J. C. \& Féres-Carneiro, T.

(2019). A cultura medicalizante e os

processos transgeracionais. Rev.CES

Psico, 12(2), 141-150.

\section{Open access}

(c) Copyright

Licencia creative commons

Etica de publicaciones

Revisión por pares

Gestión por Open Journal System

DOl: http://dx.doi.org/10.21615/

cesp. 12.2 .10

ISSN: 2011-3080

Sobre los autores:

1. Doutoranda em Psicologia Clínica.

Mestre em Psicologia Clínica.

Especialista em Psicoterapia de

Família e Casal. Psicanalista clínica e

participa de pesquisas no Laboratório

de Pesquisas em Família e Casal na

PUC-Rio.

Comparte

f06.

\section{Resumo}

0 presente trabalho tem o intuito de refletir a relação entre a cultura medicalizante e os processos transgeracionais. No cenário contemporâneo, observamos a crescente codificação dos sofrimentos psíquicos em termos de uma nomeação própria do discurso médico, mais precisamente psiquiátrico, que são amplamente socializados através da mídia e da escola. Nesse sentido, cabe pensar que os procedimentos de medicalização, surgidos nos cuidados com a população adulta, foram estendidos também às crianças. Partindo de observações clínicas, nos deparamos com um número cada vez maior de crianças desatentas ou inquietas, que demandariam um cuidado especial de seus professores e familiares, que passaram a ser diagnosticadas com transtorno de déficit de atenção e hiperatividade (TDA/H). Contudo, a prática psicanalítica com crianças se destaca por ser uma área do conhecimento que apresenta significativas especificidades, incluindo a imprescindível abertura de espaço para a escuta dos pais nas entrevistas preliminares e o trabalho com eles, quando necessário. Assim, por estar incluído o trabalho com os pais e por parecer uma alternativa diante da medicalização desenfreada, se faz necessário um constante aprofundamento teórico das peculiaridades da clínica infantil articulada às relações familiares, por possuírem caráter estruturante na constituição do sujeito criança.

Palavras-chave: Transmissão Psíquica, Sintoma Infantil, Psicanálise, Crianças, Medicalização.

\section{Abstract}

This study aims to reflect on the focuses of medicalizing culture on transgenerational processes and child symptoms. In the contemporaneous scenario, the codification of suffering in terms of a type of naming framed within medical discourse grows, more precisely psychiatric discourse, which is broadly socialized, and orders the relations of the subject with his/her own subjectivity. In this sense, it is worth thinking that the medicalization procedures, which arise in contact with the adult population, have been extended also to children. Based on clinical observations, we can see that there is a growing number of distracted or restless children, that would demand special care from their teachers and family members, that would be diagnosed 
Pág 142

2. Pós-doutoranda Terapia Familiar e de Casal. Doutora Psicologia Clínica. Professora Titular do Departamento de Psicologia (PUC-Rio) e Coordenadora do Curso de Especialização em Psicoterapia de Família e Casal da PUC-Rio. with attention deficit hyperactivity disorder (ADHD). However, the psychoanalytical practice with children stands out as an area of knowledge that presents significant specificities, including the opening of a space to listen to the parents in the preliminary interviews and to work with them, when necessary. Thus, since working with parents is included and for seeming to be an alternative to unchecked medicalization, constant theoretical study of the peculiarities of child psychoanalytical practice articulated to family relations becomes necessary, since it possesses a structuring character in the constitution of the child subject.

Keywords: Psychic Transmission, Child Symptom, Psychoanalysis, Children, Medicalization.

\section{Resumen}

El presente trabajo tiene el propósito de reflexionar sobre la relación entre la cultura medicalizante y los procesos transgeneracionales. En el escenario contemporáneo, observamos la creciente codificación de los sufrimientos psíquicos en términos propios del discurso médico, más precisamente psiquiátrico, que son ampliamente socializados a través de los medios de comunicación y la escuela. En ese sentido, cabe pensar que los procedimientos de medicalización, surgidos en los cuidados con la población adulta, se extendieron también a los niños. A partir de observaciones clínicas, nos encontramos con un número cada vez mayor de niños desatentos o inquietos, que demandan un cuidado especial de sus profesores y familiares, que son diagnosticados con trastorno de déficit de atención e hiperactividad (TDA/H). Sin embargo, otras áreas del conocimiento como la práctica psicoanalítica con niños se destaca por presenta especificidades, incluyendo la apertura de un espacio para escuchar a los padres en las entrevistas preliminares y trabajar con ellos, cuando sea necesario. Así, por estar incluido el trabajo con los padres y por parecer una alternativa ante la medicalización desenfrenada, se hace necesario una constante profundización teórica de las peculiaridades de la clínica infantil articulada a las relaciones familiares, dado su carácter estructurante en la constitución del niño.

Palabras clave: Transmisión Psíquica, Síntoma Infantil, Psicoanálisis, Niños, Medicalización.

\section{Introdução}

A contemporaneidade tem sido objeto de investigação de diversos campos do saber, tendo em vista os complexos fatores que marcam significativa presença no cenário atual. Cada vez mais, observamos a proliferação de diagnósticos psiquiátricos que incidem sobre a infância, cujos sintomas passaram a ser reconhecidos como manifestações de desordem da bioquímica cerebral e, portanto, mobilizam a prescrição e o consumo, muitas vezes abusivos, de psicofármacos. A partir da clínica psicanalítica com crianças, podemos notar o crescente entrelaçamento entre os sofrimentos psíquicos dos pacientes e o discurso medicalizante. É frequente recebermos na clínica pacientes portando diagnósticos psiquiátricos, queixando-se de sintomas diversos que, em geral, fazem parte do discurso médico e são atrelados a essa forma excessivamente fisiológica para nomear o sofrimento.

Com o avanço das neurociências e a disseminação cultural do discurso médico, a linguagem para designar o mal-estar inerente à condição humana parece estar profundamente atravessada pelo materialismo biológico, desconsiderando outros aspectos relevantes da existência do sujeito, inclusive, o contexto no qual ele está inserido. 
Pág 143

À medida que os discursos e práticas da medicina se difundem e penetram no tecido social, os indivíduos e a sociedade vão sendo produzidos por eles e se moldando ao saber médico. O próprio viver passa a ser capturado pelo discurso médico: quase toda tristeza passa a ser vivenciada como sinal de depressão (Aguiar, 2004).
Em função disso, torna-se relevante estudar a transmissão transgeracional relacionada aos cuidados dispensados às crianças e à produção de sintomas. Esta reflexão enfatiza a importância das relações familiares tanto na formação como nos desdobramentos dos sintomas.

Com efeito, a família destaca-se por ser a matriz privilegiada por onde perpassa o processo de transmissão geracional. Para Travaglia (2003), o grupo familiar é o lugar da colagem imaginária e das dinâmicas identificatórias. Entretanto, por ocasião das particularidades que atravessam os indivíduos na contemporaneidade como a terceirização dos cuidados com as crianças, a cultura medicalizante, a medicalização da infância e dos sintomas infantis, entre outros, cabe pensar a existência de um hiato, uma falta no que tange a transmissão da função parental. De acordo com a teoria psicanalítica, os cuidados fazem parte da função parental, no entanto, a tarefa de cuidar tem sido cada vez mais delegada aos especialistas, que a realizam partindo de uma suposição de patologia.

Diante disso, esta reflexão visa investigar a articulação entre a cultura medicalizante, a transmissão transgeracional e os sintomas infantis. Para tanto, inicialmente serão apresentadas considerações sobre a cultura medicalizante e sua repercussão na infância para, posteriormente, articularmos as noções de sintoma infantil e transgeracionalidade.

\section{Os efeitos da cultura medicalizante na infância}

0 conceito de medicalização foi inicialmente proposto por Irving Zola, em 1972, ao se referir à expansão da jurisdição da profissão médica para novos domínios, em particular aqueles que diziam respeito aos problemas considerados da ordem moral, legal ou criminal. Os teóricos críticos da medicalização consideravam a medicina como um agente de controle social ao passo que ela transformava fenômenos sociais como o alcoolismo, a homossexualidade, o aborto e o uso de drogas, em conceitos médicos, incluindo essas questões no domínio do saber e das instituições médicas. Paulatinamente, na modernidade, a medicina foi assumindo uma função de regulação social que antes era exercida pela Igreja e pelo judiciário (Aguiar, 2004).

Birman (2012) pontua que a modernização ocidental se fundou no projeto de medicalização social, de modo que os discursos médicos - permeados pelas categorias de normal, anormal e patológico - foram os modelos arqueológicos para a constituição dos diferentes discursos das ciências humanas.

Embora o poder da medicina não opere pela coerção ou pela violência, ele produz realidades, criando práticas e discursos que engendram novas maneiras de os indivíduos entenderem, regularem e experimentarem seus corpos e sentimentos. À medida que os discursos e práticas da medicina se difundem e penetram no tecido social, os indivíduos e a sociedade vão sendo produzidos por eles e se moldando ao saber médico. 0 próprio viver passa a ser capturado pelo discurso médico: quase toda tristeza passa a ser vivenciada como sinal de depressão (Aguiar, 2004).

Duas mudanças no pensamento psiquiátrico na década de 50 contribuíram significativamente para a constituição e difusão da cultura medicalizante. Em primeiro, a criação do DSM-I, em 1952, que elencou sintomas e formas diagnósticas e sofreu sucessivas reformulações. Este manual permite que muitos acontecimentos cotidianos, sofrimentos passageiros ou outros comportamentos sejam registrados hoje 
Pág 144

O discurso médico difundido amplamente naturaliza o sofrimento infantil e se apresenta na escola de forma marcante. É comum que educadores utilizem diagnósticos diante da observação de certos problemas de aprendizagem e as encaminhem para avaliação psiquiátrica, neurológica ou psicológica (Guarido, 2007). em dia como relacionados a transtornos mentais. Em seguida, destacamos a descoberta do primeiro neuroléptico, a clorpromazina.

Atualmente, a produção de saber sobre o sofrimento psíquico tem sido associada à indústria farmacêutica, cujos medicamentos prometem aliviar os sofrimentos existenciais. A ampla gama de sintomas presentes nos manuais, bem como as formas diagnósticas propostas por eles permitem que muitos acontecimentos cotidianos, sofrimentos passageiros ou outros comportamentos, possam ser registrados como sintomas próprios dos transtornos mentais (Guarido, 2007).

Nos últimos trinta anos, reforçou-se uma tendência de pensar todos os conflitos e dificuldades em termos médicos, mais especificamente psiquiátricos. Baseada nos avanços das neurociências, a psiquiatria supõe dominar os melhores instrumentos científicos para regular com mais eficácia o mal-estar (Caponi, 2012).

Lima (2005) ressalta que a psiquiatria e suas categorias diagnósticas têm sido um meio de transmissão da cultura ao cotidiano dos sujeitos. Nas duas últimas décadas, ao privilegiar as concepções biológicas dos transtornos mentais, a psiquiatria reforçou o processo de medicalização de condutas e estados emocionais. Um número progressivamente maior de categorias psiquiátricas tem sido criado a cada nova classificação diagnóstica, cujas descrições têm avançado sobre áreas que nem sempre foram tidas como passíveis de abordagens fisicalistas.

Por exemplo, o denominado "Transtorno de déficit de atenção/hiperatividade" (TDA/H), cuja grande presença no discurso médico e na mídia atuais reflete e alimenta uma atmosfera social permeável, seduz pais, educadores e outros indivíduos. Fortemente associado à prescrição de psicofármacos e supostamente localizado no cérebro e determinado pela genética, este transtorno tem substituído leituras psicológicas, pedagógicas e morais na descrição de comportamentos considerados inadequados. Nos seus domínios, condutas e afetos são reduzidos a epifenômenos das atividades das redes neuroquímicas cerebrais na medida em que eventos psíquicos como a atenção são tomados como meros acessórios da fisiopatologia neural (Lima, 2005).

Whitaker (2016) corrobora o pensamento de Lima (2005) acrescentando que o diagnóstico de TDA/H, durante os anos 1980 e início dos anos 1990, foi um fenômeno majoritariamente americano. No Brasil, o diagnóstico de TDA/H abriu caminho para a medicalização da infância e para a criação de um mercado global para os estimulantes como tratamentos do Transtorno.

O metilfenidato, comercializado como Ritalina, aumenta a atividade da dopamina no cérebro, bloqueando as moléculas que removem a dopamina da fenda sináptica entre os neurônios e transportando-a de volta para o neurônio pré-sináptico. De fato, os estimulantes produzem uma mudança característica nas crianças. As crianças tratadas desse modo se movem menos, socializam menos e sua atenção pode se tornar mais focada em uma tarefa específica. Esta mudança é vista como uma redução dos sintomas de TDA/H (Whitaker, 2016; Lima, 2005).

O discurso médico difundido amplamente naturaliza o sofrimento infantil e se apresenta na escola de forma marcante. É comum que educadores utilizem diagnósticos diante da observação de certos problemas de aprendizagem e as encaminhem para avaliação psiquiátrica, neurológica ou psicológica (Guarido, 2007). 
Pág 145

Observamos a presença de diagnósticos psiquiátricos que passam a estabelecer as bases biológicas do sofrimento psíquico. A ação desses fatores teve por efeito a perda da noção de sentido/ significado dos sintomas e dos sofrimentos subjetivos.
Diante desse panorama, consideramos que a presente discussão suscita mais perguntas do que respostas. Pensar que os processos psíquicos se ancoram na biologia não significa dizer que se restrinjam a ela. De fato, sem o aparato biológico, a existência não é possível. Contudo, os processos provenientes do funcionamento orgânico, cerebral, se complexificam e se desdobram em outros fatores que não se restringem a determinada localização cerebral ou aos marcadores biológicos. A própria representação neural do corpo no cérebro é mediada pelo imaginário. Sendo assim, diferentemente da visão em que a subjetividade é efeito da biologia, compreendemos a constituição da subjetividade a partir das relações, das identificações, das fantasias, entre outros fatores que se apresentam desde os primórdios da vida. A família entra em cena em função da extrema relevância que assume nesse jogo de forças, posto que desempenha um papel estratégico no engendramento de indivíduos.

Para Caliman (2016), faz-se necessário fortalecer no cuidado à infância uma constelação de sensibilidades e práticas sempre inscritas na trama cotidiana das relações intersubjetivas. Sendo assim, pensar nos processos de medicalização também significa pensar nas estratégias de cuidado com as crianças. Temos um campo complexo que adquire características distintas, onde se entrelaçam os desafios dos gestores de políticas públicas, dos profissionais (da saúde e da saúde mental, da educação, da assistência social, da cultura, etc.), dos pesquisadores, dos familiares e das próprias crianças.

Na história recente, a cultura medicalizante incide no tratamento do sofrimento psíquico. 0 diagnóstico passou a nomear a relação entre o indivíduo e o sofrimento, marcando um ponto crucial na constituição subjetiva. Assim, observamos a presença de diagnósticos psiquiátricos que passam a estabelecer as bases biológicas do sofrimento psíquico. A ação desses fatores teve por efeito a perda da noção de sentido/significado dos sintomas e dos sofrimentos subjetivos. Devemos repensar os avanços da medicalização como forma majoritária de intervenção terapêutica, bem como a dimensão do seu alcance, tendo em vista que os cuidados com a população adulta foram estendidos às crianças.

\section{Especificidades do sintoma infantil e a transgeracionalidade}

A clínica psicanalítica, desde a descoberta do inconsciente por Freud, comporta uma especificidade distante do enfoque medicalizante, em especial, no que tange ao sintoma infantil. Se o discurso médico, por um lado, atribui uma materialidade biológica à origem do sintoma, sobre o qual incidem suas intervenções, por outro lado, a psicanálise atribui, a ele, um sentido intimamente articulado à existência particular da qual o sujeito é portador. Freud atribui uma historicidade existencial ao sintoma, inaugurando, assim, o campo da psicanálise.

Desse modo, não rejeitando todo e qualquer uso de psicofármacos, o sintoma infantil pode ser compreendido para além do sentido estrito do discurso médico. Com o intuito de dar voz à criança, considerando o contexto cultural em que ela está inserida, bem como as suas relações com a escola e com a família, estudamos - à luz da teoria psicanalítica - as especificidades do sintoma infantil, propondo uma articulação entre o sintoma e a transgeracionalidade. Nesse sentido, cabe refletir sobre o enlace entre a medicalização, o sintoma apresentado pela criança e a transmissão psíquica.

Rudge (2012) afirma que o saber analítico é um instrumento construído por Freud para interrogar a lógica inconsciente subjacente a um sintoma, ou seja, aquilo que incomoda e que causa certo dano ao sujeito que dele padece. Por sua vez, Travaglia (2003) aponta 
Féres-Carneiro (1980) pontua, em seu estudo a respeito da relação conjugal e suas repercussões no comportamento dos filhos, que -na maioria das vezes-os distúrbios apresentados pela criança encontram suas raízes na relação dos pais. que os laços familiares são os mediadores entre o sujeito e a linguagem, fornecendo os significantes com que cada um vai tecer a sua história, construindo uma sintaxe particular, a sua trama gramatical. Assim, a posição subjetiva vai definir-se pela maneira como o sujeito é afetado pelo significante. Os detritos de linguagem marcam o psiquismo de forma particular, transcendendo o sentido, ordenam e determinam os alicerces das cadeias significantes que serão construídas. Os sons que o sujeito ouve, que se presentificam no discurso familiar, com os quais ele terá que lidar para interpretá-los, constituirão os fundamentos do seu inconsciente e de seu sintoma.

De outro modo, Meyer (1983) destaca que o padrão de atitudes parentais também estará relacionado ao meio ambiente cultural, ao mesmo tempo em que irá definir os papéis dos membros da família e estabelecer as bases de suas interações. Diante dessa perspectiva, a dinâmica do relacionamento do casal tem a propensão de tornar-se a dinâmica familiar; assim, o casal recém-formado é o "veículo de transporte" das expectativas e necessidades que foram cunhadas em uma situação ancestral.

A família enquanto grupo específico, caracterizado por vínculos de aliança de parentesco e filiação, pelas proibições que regem estes vínculos, articula as relações entre os diferentes membros e entre as diferentes gerações, em função da história e dos próprios mitos. Contudo, a família também pertence ao conjunto social e cultural e, desse modo, deve articular o lugar de cada um dos seus membros com seu lugar no conjunto social.

Féres-Carneiro (1980) pontua, em seu estudo a respeito da relação conjugal e suas repercussões no comportamento dos filhos, que -na maioria das vezes- os distúrbios apresentados pela criança encontram suas raízes na relação dos pais. A autora ressalta que uma intervenção com o casal pode ser suficiente para que haja uma remissão de grande parte dos sintomas apresentados pelos filhos.

Lançamos a hipótese de que na base de um sintoma infantil existiriam elementos genealógicos transmitidos em estado bruto, através da transmissão transgeracional. Nesse ponto da discussão, cabe supor que estaria havendo uma lacuna, uma falta sendo transmitida de geração em geração, a saber, a falta da capacidade de cuidar, tão importante e necessária, àqueles que desempenham função parental, para a constituição dos sujeitos. Esse hiato que vem sendo transmitido se encontra aliado a uma cultura medicalizante e a terceirização dos cuidados com as crianças.

Dolto (1988) compreende que a criança encarna e presentifica - através dos seus sintomas - as consequências de um conflito vivo, familiar ou conjugal, camuflado e aceito por seus pais. Cabe a ela suportar, inconscientemente, o peso das tensões e interferências da dinâmica emocional sexual inconsciente em ação nos pais, cujo efeito de contaminação mórbida é tanto mais intenso quanto mais se guarda, ao seu redor, o silêncio e o segredo. Logo, seguindo a teoria psicanalítica, os sintomas infantis manifestos são uma ressonância às angústias ou aos processos reativos às angústias dos pais.

A neurose dos pais tem um papel crucial na eclosão dos sintomas da criança, pois esta fixa a sua existência num lugar determinado pelos pais no seu sistema de fantasias e desejos. A criança procura responder ao enigma dos significantes obscuros propostos pelos adultos, identificando-se com o que julga ser o objeto materno, tentando preencher a falta estrutural e evitar a angústia de castração. 
Pág 147

A família desempenha um papel primordial na transmissão da cultura, estabelecendo à aquisição da língua (legitimamente chamada de materna), a repressão dos instintos, a manutenção dos ritos, dos costumes e das tradições. Através destes processos fundamentais para o desenvolvimento psíquico, a família transmite estruturas de comportamento e representações cujo funcionamento ultrapassa os limites da consciência.
No texto "Nota sobre a criança" (1969), Lacan afirma que a função de resíduo exercida (e mantida) pela família conjugal, na evolução das sociedades, destaca a irredutibilidade de uma transmissão. Esta seria da ordem de uma constituição subjetiva. Na concepção de Jacques Lacan, o sintoma da criança acha-se em condição de responder ao que há de sintomático na estrutura familiar. 0 sintoma, dado fundamental da experiência analítica, neste contexto se define como representante da verdade, podendo representar a verdade do casal familiar. Em uma das posições que a criança pode vir a assumir, ela realiza a presença do "objeto a" na fantasia materna.

Em outro momento de seu ensino, Lacan (1938) postula que a espécie humana caracteriza-se por um desenvolvimento singular das relações sociais, sustentado por capacidades excepcionais de comunicação. A conservação e progresso da espécie, por dependerem da comunicação, são acima de tudo uma obra coletiva e constituem a cultura. Esta introduz uma nova dimensão tanto na realidade social como na vida psíquica. Nessa conjuntura, a família desempenha um papel primordial na transmissão da cultura, estabelecendo à aquisição da língua (legitimamente chamada de materna), a repressão dos instintos, a manutenção dos ritos, dos costumes e das tradições. Através destes processos fundamentais para o desenvolvimento psíquico, a família transmite estruturas de comportamento e representações cujo funcionamento ultrapassa os limites da consciência.

A continuidade psíquica entre as gerações se revela desde o totem até o nome patronímico, se manifestando como uma transmissão à inclinações psíquicas. 0 complexo de Édipo coloca em relevo as particularidades das relações familiares para a constituição psíquica. O movimento do Édipo opera por um conflito triangular no sujeito. As formas sob as quais se perpetuam os seus efeitos podem ser designadas como supereu e ideal do eu. Uma análise mais estrutural da identificação edipiana permite observar que, em razão de uma identificação do sujeito com a imago do genitor do mesmo sexo que o supereu e o ideal do eu podem revelar à experiência traços segundo as particularidades dessa imago (Lacan, 1938).

Sob uma outra perspectiva, Lahaye, Desmet e Pourtois (2007) afirmam:

${ }^{1}$ Qui sommes-nous? D'où venons-nous? Où allons nous? Depuis longtemps, l'homme se pose trois questions existentielles. L'homme vise ainsi à mâ̂triser le présent, à connaître ses origines et à prévoir son avenir. Parmi les réponses possibles a ces questions, deux tendances se distinguent. Elles conduisent à deux philosophies différentes. La première est celle de la liberté. La seconde privilégie de déterminisme. La philosophie de la liberté met accent sur le changement. (...) Le monde est en perpétuel changement et le sujet ne peut traverser ces mutations sans être lui-même transformé. (...) À l'inverse de la conception libératrice, la philosophie déterministe met l'accent sur a continuité. La liberté n'est jamais qu'une illusion que se donne l'homme. Elle lui laisse croire qu'il maîtrise son destin mais en fait, il est prisonnier de son histoire et il reproduit les habitudes de vie, les valeurs, les pratiques sociales

1. "Quem somos? De onde viemos? Aonde vamos? Há muito tempo o homem se faz essas três perguntas existenciais. Desse modo, o homem vis controlar o presente, conhecer suas origens e prever seu futuro. Entre as possíveis respostas a essas perguntas, duas tendências se destacam. Eles levam a duas filosofias diferentes. A primeira é a da liberdade. A segunda favorece o determinismo. A filosofia da liberdade enfatiza a mudança. ( $)$ mundo está em perpétua mudança e o sujeito não pode passar por essas mutações sem ser ele mesmo transformado. (.) Ao contrário da concepço 0 libertadora a filosofia deteminista en atiza a continudade. A liberdadé́ apensuma ilusão que o homem se d́. Ela odeixa acreditar que ele domin seu destino, mas na verdade, ele é prisioneiro de sua história e reproduz os hábitos de vida, os valores, as práticas sociais e culturais que ele herdou. A continuidade estaria, portanto, mais ancorada nas relações humanas do que a ruptura ou a mudança, e isso também se aplicaria ao desenvolvimento das sociedades no longo prazo (...) Enquanto lugar primeiro de educação, a família está no centro dessas duas filosofias que atravessam a história dos homens. Ela submete a criança a uma dupla injunção que diz respeito, ao mesmo tempo, à liberdade e ao determinismo. Por um lado, a educação transmitida inclui uma mensagem de emancipação (seja diferente de nós, seja melhor do que nós). por outro lado, a pedagogia das famílias transmite para a criança um modelo a ser reproduzido (seja como nós, respeite nossos valores). Paradoxalmente, essas duas condições de educação tendem a se fortalecer com o tempo (p.43)." 
A pedagogia operatória e racional das famílias modernas deu lugar à educação relacional e emocional da geração pós-moderna. Essa transformação dos processos de aprendizagem traduz uma mutação de valores. Assim, a sociologia e a clínica se cruzam, estabelecendo uma sinergia entre a história e o sujeito afim de que o ator possa, em algum momento, ter consciência do que lhe foi transmitido (Lahaye, Desmet \& Pourtois, 2007). et culturelles dont il a hérité. La continuié serait donc plus ancrée dans les rapports humains que ne le seraient la rupture ou le changement et cela vaudrait également pour le développement des sociétés à long terme (...) En tant que premier lieu d'éducation, la famille est au centre des deux philosophies qui traversent l'histoire des hommes. Elle soumet l'enfant à une double injonction qui relève à la fois de la liberté et du determinisme. D'une part, l'éducation transmise comprend un message d'émancipation (sois différent de nous, sois mieux que nous), d'autre part, la pédagogie des familles transmet à l'enfant un modèle à reproduire (sois comme nous, respecte nos valeurs). $\mathrm{Pa}$ radoxalement, ce deux conditions de l'éducation ont tendance à se renforcer au cours de temps (p.43).

Conforme a compreensão destes autores, a família encontra-se no centro de duas tendências filosóficas que atravessam a história humana. Ao passo que as famílias acentuam o efeito de rupturas sobre várias gerações, elas também garantem a transmissão da continuidade, ou seja, a passagem de uma herança sociocultural. Assim, as mudanças sociais interferem na transmissão de conteúdo entre as gerações. 0 imperativo de transmissão que acompanha a ordem de filiação permite a sociedade se perpetuar respeitando, porém, as mesmas regras fundadoras.

A genealogia permite colocar os sujeitos em uma ordem simbólica para que eles possam se diferenciar uns dos outros. Esta ordem simbólica da genealogia justifica a transmissão que se opera através de uma cadeia geracional. Essa função de transmissão se impõe como a regra de uma ordem social. De uma geração a outra, os pais não educam as crianças da mesma maneira. A pedagogia operatória e racional das famílias modernas deu lugar à educação relacional e emocional da geração pós-moderna. Essa transformação dos processos de aprendizagem traduz uma mutação de valores. Assim, a sociologia e a clínica se cruzam, estabelecendo uma sinergia entre a história e o sujeito afim de que o ator possa, em algum momento, ter consciência do que lhe foi transmitido (Lahaye, Desmet \& Pourtois, 2007).

Segundo as pontuações de Lahaye, Desmet e Pourtois (2007), em um estudo longitudinal, as práticas educativas permanecem estáveis de uma geração a outra, ou seja, o capital social, pedagógico, cultural e simbólico das famílias. Nesta leitura, a vida cotidiana do grupo familiar é um modo privilegiado de inculcação dos hábitos. A repetição de rituais cotidianos (refeições, lazer, leituras, conversas, tarefas domésticas etc.) são realizações que se impregnam nos membros da família e formam hábitos. Estes, enquanto estruturas psíquicas predispõe o indivíduo a pensar, a agir ou reagir de determinada maneira, apreciar ou depreciar certos objetos, atos ou pensamentos. De outro modo, os hábitos orientam a maneira como o indivíduo apreende os eventos que se apresentam ou que vão se apresentar. 0 hábito molda a forma de antecipação e, esta antecipação modelada pelo hábito é designada pelo termo "protension" (Lahaye, Desmet, \& Pourtois, 2007).

Ao pensar sobre o lugar privilegiado da família, Lima (2005) compreende que ela não consegue mais proporcionar um espaço protegido, no qual a transmissão de valores morais não se mostre subjugada à lógica do consumo, das relações superficiais, da exploração e da inconstância permanente. A criança passa a julgar os pais de acordo com sua possibilidade de proporcionar-lhe os produtos que deseja e, por seu turno, os próprios pais passam a pautar sua autoridade na capacidade de prover o lar de bens materiais. Assim, a lógica do próprio interesse e da eficácia econômica destrói 
Pág 149

Torna-se imprescindível se fazer operar uma clínica que coloque a criança numa posição de sujeito perante sua história e perante sua vida, sem recorrer a soluções simplistas que desconsiderem sua inserção no discurso parental e social/escolar. Por isso, é necessário compreender o lugar que foi designado à criança em uma história feita de diversos acontecimentos, desejos e palavras ditas e não ditas para, por fim, entendermos o que poderia ter alienado a criança a determinados significantes. a lógica da organização familiar baseada na deferência e inviabiliza a sua sustentação apenas pelo vínculo afetivo.

A decadência da autoridade parental faz decair também a influência dos pais sobre os filhos e o potencial de identificação destes com os primeiros. Como resultado, temos jovens que descartam a mediação de seus genitores com a cultura, posto que não os consideram em sintonia com as exigências sociais. Partindo deste ponto de vista, haveria uma permissividade que testemunha a impossibilidade de os pais atuarem como modelos de identificação para os filhos. Desse modo, a única saída seria abdicar a transmissão de preceitos tradicionais da cultura em nome da moldagem de personalidades adaptadas à realidade do mundo e à lógica de consumo (Lima, 2005).

A propagação avassaladora da cultura medicalizante (e de consumo) -assim como sua ressonância sobre a família- podem produzir inúmeros desdobramentos que merecem ser minusciosamente aprofundados. Contudo, enfatizamos que é preciso que se compreendam os diagnósticos como processos extremamente complexos, sem circunscrevê-los em um viés que tende a biologizar as relações sociais, afetivas e a legitimá-lo nas escolas, nas famílias e na sociedade. Os processos medicalizantes delimitam o indivíduo, normatizam-no, minando suas possibilidades de se posicionar histórica e politicamente. Pode-se compreender a medicalização como uma necessidade de se silenciar o sofrimento a qualquer custo, como se não devesse fazer parte dos processos de desenvolvimento humano.

\section{Considerações finais}

Conforme foi visto nesta reflexão, é de suma importância não restringir a sintomatologia apresentada pela criança à perspectiva médica, visto que a resposta sintomática da criança tem a marca das suas construções enquanto sujeito, com as suas respectivas responsabilidades e implicações. Nesse sentido, torna-se imprescindível se fazer operar uma clínica que coloque a criança numa posição de sujeito perante sua história e perante sua vida, sem recorrer a soluções simplistas que desconsiderem sua inserção no discurso parental e social/escolar. Por isso, é necessário compreender o lugar que foi designado à criança em uma história feita de diversos acontecimentos, desejos e palavras ditas e não ditas para, por fim, entendermos o que poderia ter alienado a criança a determinados significantes.

Na clínica com crianças, é crucial procurar escutar o que significa para ela seu sintoma, qual o sentido fundamental da dinâmica do mesmo e quais as possibilidades que ele preserva ou compromete. Entender que a criança é sujeito de um grupo coloca para o psicanalista uma questão fundamental: de que modo conceber e tratar o sujeito como tendo a si mesmo como o próprio fim e como elo, servidor, beneficiário e herdeiro de uma cadeia intersubjetiva à qual ele está submetido? Assim, escutar analiticamente certas histórias das crianças e de seus pais thes concede a oportunidade de serem compreendidos e de construírem conjuntamente novos significados.

Finalmente, enfatizamos a importância e a necessidade de serem articulados os saberes médicos, pedagógicos e psicológicos com o intuito de promover saúde, salientando que o trabalho interdisciplinar não deve prescindir jamais da participação familiar, para a construção de uma ética do cuidado que transcenda a medicalização de adultos e crianças. 


\section{Referências}

Aguiar, A. (2004). A psiquiatria no divã: entre as ciências da vida e a medicalização da existência. Rio de Janeiro: Relume Dumará.

André-Fustier, F., \& Aubertel, F. (1998). A transmissão psíquica familiar pelo sofrimento. In: Eiguer, Alberto (Org.), A transmissão do psiquismo entre gerações. São Paulo: Unimarco Editora.

Birman, J. (2012). O sujeito na contemporaneidade. Rio de Janeiro: Editora Civilização Brasileira.

Caliman, L. (2016). Infâncias medicalizadas: para quê psicotrópicos para crianças e adolescentes? In S. Caponi, M. Vásquez-Valencia \& M. Verdi (Orgs.), Vigiar e medicar: estratégias de medicalização da infância (pp.47-60). São Paulo: LiberArs.

Caponi, S. (2012). Loucos e degenerados: uma genealogia da psiquiatria ampliada. Rio de Janeiro: Editora FIOCRUZ.

Dolto, F. (1988). Prefácio. In M. Mannonni, A primeira entrevista em psicanálise. 6. ed. Rio de Janeiro: Campus.

Féres-Carneiro, T. (1980). Psicoterapia de casal e suas repercussões no comportamento dos filhos. Arquivos Brasileiros de Psicologia, 32(4), 51-60.

Figueiredo, L.C. (2009). As diversas faces do cuidar: considerações sobre a clínica e a cultura. In M. Maia (Org.), Por uma ética do cuidado (pp.121-141). Rio de Janeiro: Garamond.

Guarido, R. (2007). A medicalização do sofrimento psíquico: considerações sobre o discurso psiquiátrico e seus efeitos na educação. Educação e pesquisa-USP, São Paulo: USP, 33 (1), 151-161.

Kaës, R. (1998). Os dispositivos psicanalíticos e as incidências da geração. In Eiguer, Alberto (Org.). A transmissão do psiquismo entre gerações. São Paulo: Unimarco Editora.

Lacan, J. (2008). Complexos familiares. Rio de janeiro: Jorge Zahar. (Trabalho originalmente publicado em 1938).

Lacan, J. (1969). Outros escritos. Rio de Janeiro: Jorge Zahar.

Lahaye, W., Desmet, H., \& Pourtois, J.P. (2007). L'héritage de la transmission. La revue internationale de l'éducation familiale: D'une génération à l'autre, 22(2), 43-66.

Lima, R. C. (2005). Somos todos desatentos?: 0 TDA/H e a construção das bioidentidades. Rio de Janeiro: Relume Dumara.

Meyer, L. (1983). Família: dinâmica e terapia. São Paulo: Brasiliense.

Rudge, A. M. (2012). Método clínico, ciência e subjetividade. Revista Latinoamericana de Psicopatologia Fundamental, 15(2), 235-239. http://dx.doi.org/10.1590/ S1415-47142012000200001

Travaglia, I. (2003). Família: um dos nomes do mal estar. In Meira, Yolanda Mourão (Org.). O porão da família: ensaios de psicanálise. São Paulo: Casa do Psicólogo.

Whitaker, R. (2016). Transformando crianças em pacientes psiquiátricos: fazendo mais mal do que bem. In S. Caponi, M. Vásquez-Valencia \& M. Verdi (Orgs.), Vigiar e medicar: estratégias de medicalização da infância (pp.29-45). São Paulo: LiberArs.

Zola, I. (1972). Medicine as an institution of social control. Sociological Review, 20, 487-503. http://doi.org/10.1111/j.1467-954X.1972.tb00220.x 